\title{
Study of mechanical, microstructural and thermal stability properties of friction stir processed aluminum 2024-T3 alloy
}

\author{
M. Regev ${ }^{1 *}$, S. Spigarelli ${ }^{2}$ \\ ${ }^{1}$ Department of Mechanical Engineering, ORT Braude College, P.O. Box 78, Karmiel 21982, Israel \\ ${ }^{2}$ Dipartimento di Ingegneria Industriale e Scienze, Matematiche (DIISM), Università Politecnica delle Marche, \\ Via Brecce Bianche, Ancona I-60131, Italy
}

Received 9 March 2019, received in revised form 2 April 2019, accepted 12 April 2019

\begin{abstract}
Friction Stir Processing (FSP) was applied on AA2024-T3 plates. The hardness and tensile properties of the stir zone were tested, and a microstructure study was conducted. During the FSP the coarse elongated grains of the parent material changed into fine equiaxed ones, refinement of the coarse precipitates detected at the parent material occurred at the same time. The material subjected to FSP was found to be thermally unstable, as revealed by aging experiments at $300^{\circ} \mathrm{C}$ and precipitate chemical analysis. TEM study showed that the rolled parent material contained low-angle sub-grains with dislocation network boundaries. During FSP these were replaced by fine equiaxed grains with clear boundaries and no dislocation tangles. This led to the conclusion that the material underwent Dynamic Recovery (DRV) during the rolling process, as opposed to Dynamic Recrystallization (DRX) during FSP. Thus, FSP appears to have the technological potential for improving the microstructure and mechanical properties of AA2024.
\end{abstract}

Ke y words: Friction Stir Processing (FSP), AA2024-T3, dislocations, dynamic recovery, dynamic recrystallization

\section{Introduction}

Friction Stir Processing (FSP) is a severe plastic deformation process derived from Friction Stir Welding (FSW), a process developed at The Welding Institute (TWI) in the UK in $1991[1,2]$. FSP aims to obtain a stir zone with very fine grain size. As in FSW, in FSP a non-consumable rotating tool with a shoulder and a pin traverses the parent material and produces intense plastic deformation. FSP was first reported by Mishra et al. in 2000 [1].

The $2024(\mathrm{Al}-4 \% \mathrm{Cu}-1.5 \% \mathrm{Mg})$ aluminum alloy is one of the most widely used materials for airplane structures [3] and as such has been investigated in depth to clarify the relationships between its microstructure and its mechanical properties. Unlike the case of FSW of the 2024 aluminum alloy, very few publications have investigated FSP of the 2024 aluminum alloy. The following paragraph summarizes the published studies in the field of FSP of the 2024 aluminum alloy as of today.
Nadammal et al. [2] applied a bottom-up approach for optimizing the process parameters to obtain a defect-free processed material. Their results included mechanical properties and residual stress analysis together with grain size and precipitate studies conducted using Scanning Electron Microscopy (SEM). Charit and Mishra [3] studied the superplastic behavior of friction-stir-processed AA2024-T4. Based on qualitative Transmission Electron Microscope (TEM) examination, they claimed that the grain size obtained at the stir zone was $\sim 3.9 \mu \mathrm{m}$. Cavaliere [4] also reported on the superplastic behavior of friction-stirprocessed $2024 \mathrm{Al}$ alloy and further studied the effect of the addition of Sc and $\mathrm{Zr}$, reporting on the average grain size of $\sim 1 \mu \mathrm{m}$ at the stir zone. Suri et al. [5] reported that FSP yielded an improvement in tensile strength of about $20 \%$, while they observed a negligible drop in yield strength with respect to the raw material. Concerning elongation to fracture, Suri et al. [5] pointed to a drop of approximately $40 \%$ in the case of processed material. Nadammal et al. [6] stud-

*Corresponding author: e-mail address: michaelr@braude.ac.il 
Table 1. Chemical composition of AA2024-T3 (wt.\%) [11]

\begin{tabular}{ccccccccccc}
\hline Cr max & $\mathrm{Cu}$ & Fe $\max$ & $\mathrm{Mg}$ & $\mathrm{Mn}$ & $\mathrm{Si} \max$ & $\mathrm{Ti} \max$ & Zn max & $\mathrm{Al}$ & Other, each max & Other, total max \\
\hline 0.1 & $3.8-4.9$ & 0.5 & $1.2-1.8$ & $0.3-0.9$ & 0.5 & 0.15 & 0.25 & Bal. & 0.05 & 0.15 \\
\hline
\end{tabular}

ied microstructure and texture evolution during single and multiple pass FSP. They reported on the formation of equiaxed grains with an average size of 4-5 $\mu \mathrm{m}$ at the stir zone, claiming that Dynamic Recrystallization (DRX) was the dominant mechanism while Particle Stimulated Nucleation (PSN) was a participating nucleation mechanism. Ren et al. [7] studied crack repairing by FSP in the 2024 aluminum alloy. They used optical microscopy for their microstructure study and provided microhardness profiles, but they did not conduct any quantitative analysis of the microstructure at the repaired zone.

Nevertheless, they did indicate that dynamic recrystallization was the process taking place underneath the shoulder of the tool. Ghanbari et al. [8] reported on single- and multi-pass FSP of AL2024/SiC composite. They noted that optical microscopy revealed fine equiaxed grains at the stir zone but did not report on the size of these grains. Also, they referred to the influence of the number of passes, between 1 and 4, on the hardness of the processed material, noting a decrease in hardness as the number of passes increased. El-Mahallawi et al. [9] reported on an increase in hardness, from $94 \mathrm{HV}$ in the case of the non-processed material to 114.7 for material after undergoing FSP, while the UTS values were 196 and $211 \mathrm{MPa}$, respectively. According to these researchers [9], the elongation to fracture changed from $2.7 \%$ in the case of non-processed material to $4.1 \%$ for material after undergoing FSP. Nadammal et al. [10] studied microstructure evolution during FSP of AA2024, AA2219 and AA5086 using X-ray diffraction and electron back-scattered diffraction techniques. They emphasized the role of strain-induced grain boundary migration (SIMB) and particle-stimulated nucleation (PSN) that acted simultaneously as the nucleation mechanisms for DRX in Al alloys during FSP, while in the case of AA2024 PSN, large particles of $\mathrm{Al}_{2} \mathrm{CuMg}$ became nuclei for DRX.

In addition to the limited number of publications examining FSP of the 2024 aluminum alloy, it should be noted that only two of them $[6,8]$ deal with multiple pass and its effect on the microstructure and mechanical properties of the stir zone. Moreover, it seems that none of these publications conducted an analytical TEM study of the material undergoing FSP, nor did they study its thermal stability, namely its aging behavior. Also, it is well known that the nugget zone of a friction stir weld has a wedge shape - it is as wide as the diameter of the shoulder at the upper surface of

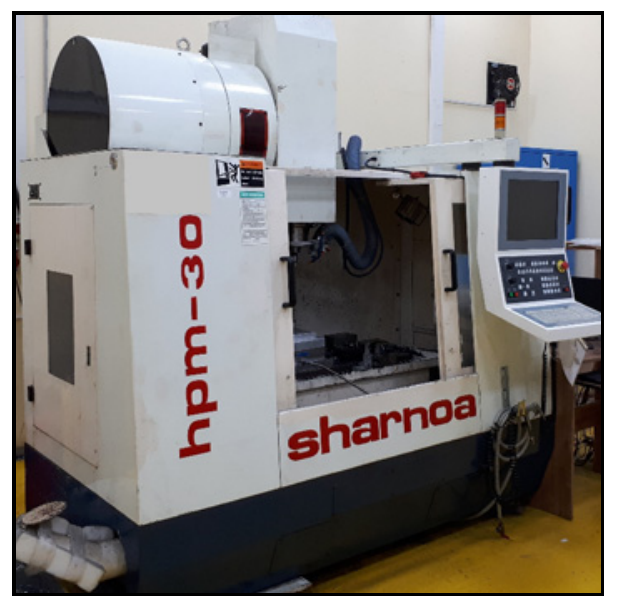

Fig. 1. The FSP machine.

the weld and markedly narrower near its opposite surface - not to mention the differences between the advancing side and the retreating surface. For these reasons, it is impossible to obtain a uniform cross-section as far as the microstructure and mechanical properties are concerned. Hence the current paper offers a new approach in which the material was processed on both sides, thus yielding a wider, rectangular and more homogenous stir zone. Aging experiments of the processed material were conducted at $300^{\circ} \mathrm{C}$ throughout $250 \mathrm{~h}$, and High-Resolution Scanning Electron Microscope (HRSEM) together with Energy Dispersive $\mathrm{X}$-ray Spectroscopy (EDS) were used to study the microstructure of the stir zone of both the processed and the aged material. Mechanical properties, namely, tension and hardness, were studied in both conditions as well. A quantitative TEM study compared the parent material and the stir zone of the FSP processed material to consider the question of whether a material with high Stacking Fault Energy (SFE), such as aluminum, is prone to DRX.

\section{Experimental procedure}

The material used for this study was commercial AA2024-T3 aluminum alloy in the form of $200 \mathrm{~mm}$ $\times 100 \mathrm{~mm}$ plates, $3.175 \mathrm{~mm}$ thick. The chemical composition of AA2024-T3 is given in Table 1 .

The above plates were subjected to FSP processing using a SHARNOA CNC milling machine, see Fig. 1.

The H-13 steel welding/processing tool used con- 

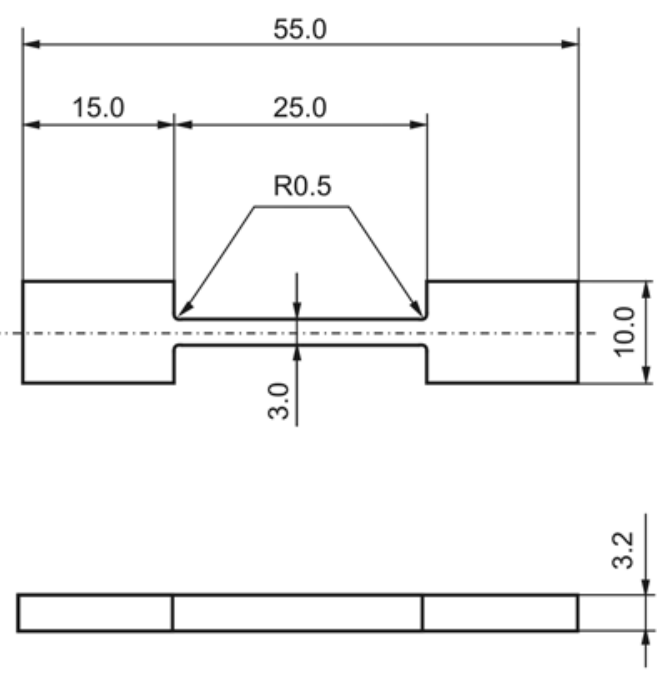

Fig. 2. Drawing of a tensile specimen.

sisted of a pin of $4.5 \mathrm{~mm}$ diameter and $3 \mathrm{~mm}$ height and a $20 \mathrm{~mm}$ diameter shoulder. A single pass was made on one side of the plate. The plate was then flipped and processed once again right above the first pass, which was on the bottom side of the plate. The second pass was made so that the advancing side of the first pass became the retreating side of the second, and vice versa. The motivation was to make the stir zone as symmetrical and uniform as possible while achieving an almost rectangular cross-section. The optimal processing parameters according to visual inspection, metallography, and finally radiography were found to be a rotational speed of $800 \mathrm{rpm}$ and a transverse speed of $80 \mathrm{~mm} \mathrm{~min}^{-1}$ as described in detail elsewhere [12]. EDS analysis was conducted on the stir zone and the parent material on both sides of the stir zone to check the chemical composition.

The metallographic study was conducted using a Zeiss AX10 optical microscope and a Zeiss Ultra Plus HRSEM. The tensile specimens were extracted from the stir zone parallel to its longitudinal axis so that the entire gage length of the specimen was made of the processed material. A drawing of a tensile specimen is given in Fig. 2. Ten tensile specimens were tested, five prepared from the parent material and the other five from the processed material. TEM investigation was conducted using an FEI Tecnai $G^{2}$ T20 TEM. The thermal stability of the microstructure was studied by means of aging experiments conducted at $300{ }^{\circ} \mathrm{C}$ for up to $280 \mathrm{~h}$. Vickers microhardness measurements were taken using a Seiki Matsuzawa microhardness tester under a load of $200 \mathrm{gf}$, while tension tests were conducted both on parent material and on processed specimens using an Instron 3369 machine.

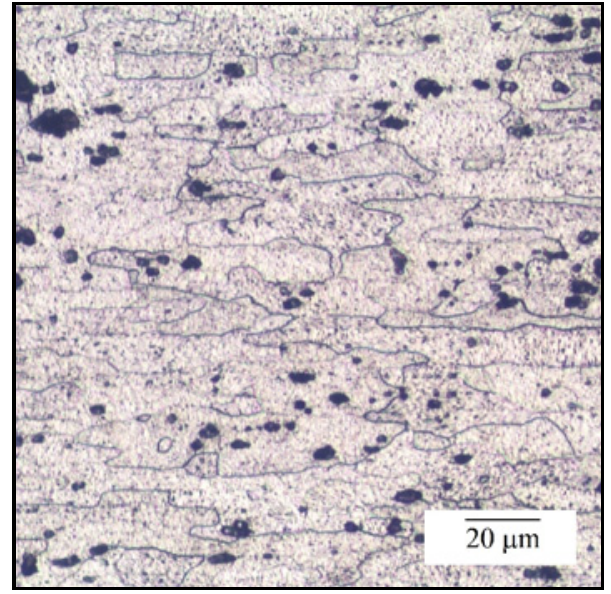

Fig. 3. Optical micrograph of the parent metal.

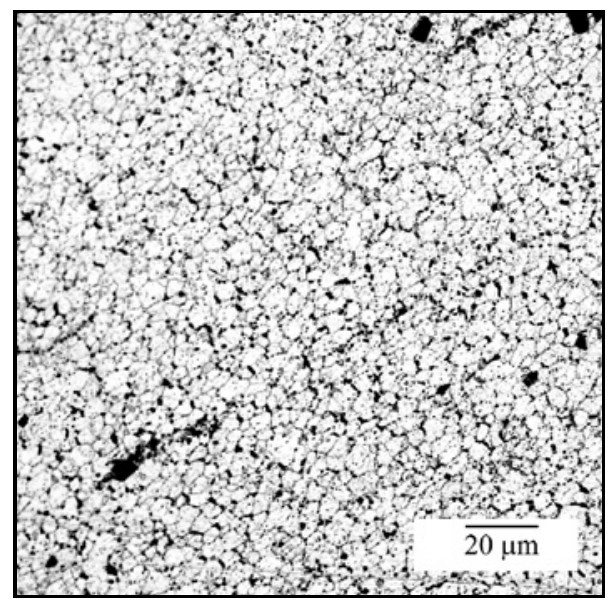

Fig. 4. Optical micrograph of the stir zone.

\section{Results}

Figure 3 depicts an optical micrograph of the parent AA2024-T3, while Fig. 4 shows an optical micrograph taken from the middle of the stir zone of the friction-stir-processed material. Both micrographs were taken under the same magnification.

Figures 3 and 4 indicate that the microstructure changed markedly during the FSP. The processed material consists of equiaxed fine grains where each grain has an average diameter of a few microns, instead of the elongated coarse grains of the parent material. The elongated grains of the parent material are due to the rolling process in this direction.

Tensile test results at room temperature for both the parent metal and the processed materials are listed in Table 2. As stated earlier, in the case of the processed material the specimens were extracted from the stir zone parallel to its longitudinal axis so that the 
Table 2. Tensile properties

\begin{tabular}{ccccccc}
\hline Condition & $\begin{array}{c}\text { Average yield } \\
\text { stress } \\
(\mathrm{MPa})\end{array}$ & $\begin{array}{c}\text { Yield stress } \\
\text { SD } \\
(\mathrm{MPa})\end{array}$ & $\begin{array}{c}\text { Average } \\
\text { tensile stress } \\
(\mathrm{MPa})\end{array}$ & $\begin{array}{c}\text { Tensile stress } \\
\text { SD } \\
(\mathrm{MPa})\end{array}$ & $\begin{array}{c}\text { Average } \\
\text { elongation to } \\
\text { fracture } \\
(\%)\end{array}$ & $\begin{array}{c}\text { Elongation to } \\
\text { fracture SD } \\
(\%)\end{array}$ \\
\hline Parent material & 362 & 3.5 & 463.6 & 1.5 & 20.9 & 1.9 \\
Processed material & 282.8 & 13.9 & 354.6 & 49 & 6.1 & 2.7 \\
\hline
\end{tabular}

Table 3. EDS analysis results (wt.\%)

\begin{tabular}{lcccccccc}
\hline & $\mathrm{Cu}$ & $\mathrm{Fe}$ & $\mathrm{Mg}$ & $\mathrm{Mn}$ & $\mathrm{Si}$ & $\mathrm{Ti}$ & $\mathrm{Zn}$ & $\mathrm{Al}$ \\
\hline Stir zone & 4.69 & 0.18 & 1.32 & 0.57 & - & 0.09 & - & 93.15 \\
Parent - left & 4.42 & 0.12 & 1.42 & 0.72 & - & - & 0.19 & 93.13 \\
Parent - right & 4.85 & 0.12 & 1.48 & 0.66 & 0.11 & 0.04 & 0.17 & 92.56 \\
\hline
\end{tabular}

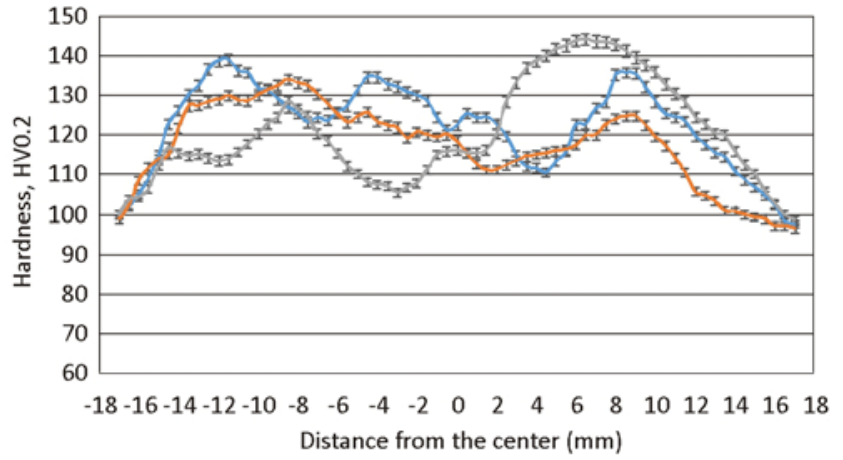

Fig. 5. Microhardness profiles of the stir zone.

entire gage length of the specimen was made of the processed material, while in the case of the parent material the longitudinal axis of the specimens was parallel to the rolling direction of the material.

As can be seen from Table 2, the tensile properties of the FSP processed material are inferior to those of the parent material. The average yield stress of the processed material was about $22 \%$ lower than the average yield stress of the parent material, while the tensile stress and the elongation to fracture dropped by about 25 and $71 \%$, respectively. It should be noted that the scattering of the results, namely, the standard deviation, is much larger in the case of the FSP processed material compared to the parent material. Figure 5 shows three microhardness profiles of the FSP processed material: profile 1 was taken as close as possible to the upper surface, profile 2 was taken at the middle of the cross-section and profile 3 was taken near the lower surface. All the measurements were taken across the stir zone, namely, perpendicular to its longitudinal axis, while the distance from one indentation to another was $0.25 \mathrm{~mm}$. As can be seen in Fig. 5 , the hardness values vary across the stir zone between 105

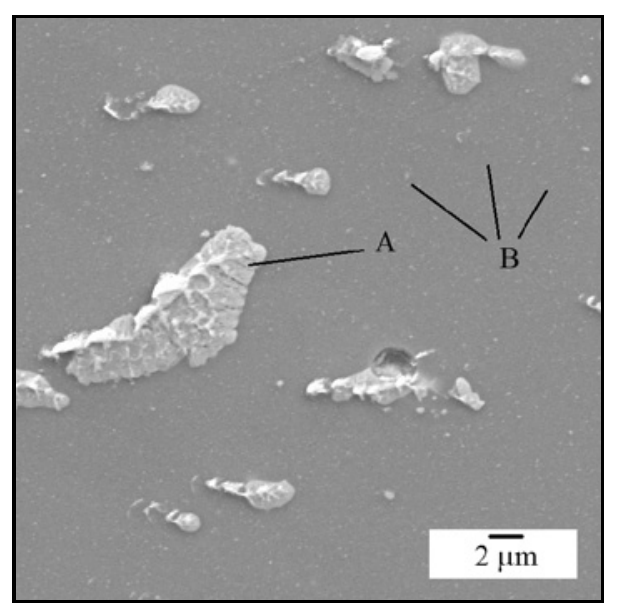

Fig. 6. HRSEM micrograph of the AA2024-T3 parent metal.

and $145 \mathrm{HV}$, while the maximum differences between the upper and lower surfaces were measured at about $4 \mathrm{~mm}$ from the center.

EDS analysis results of the stir zone and the parent material on both sides of the stir zone metal are listed in Table 3; it can be seen that the chemical composition fulfills the requirements of Table 1 .

Figure 6 depicts an HRSEM image of the parent material, while Figs. 7 and 8, respectively, show HRSEM images under the same magnification of the FSP as-processed material and the FSP processed material after $280 \mathrm{~h}$ at $300^{\circ} \mathrm{C}$.

In the case of the parent material, two kinds of precipitates are obvious - very coarse ones that are tens of microns in size (type A in Fig. 6) and evenly dispersed nano-sized precipitates (type B). In the case of the FSP as-processed material, the coarse precipitates are not discernible, and the average size of the precipitates is within the range of $0.1-1 \mu \mathrm{m}$ (type $\mathrm{C}$ in Fig. 7), 


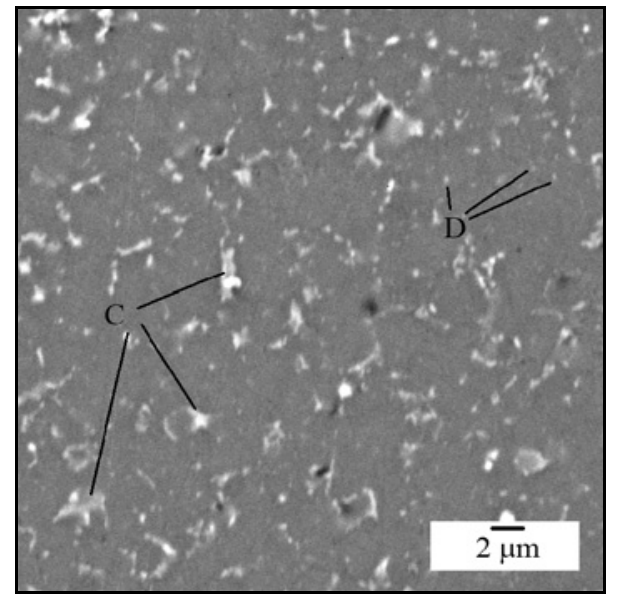

Fig. 7. HRSEM micrograph of the FSP as-processed material.

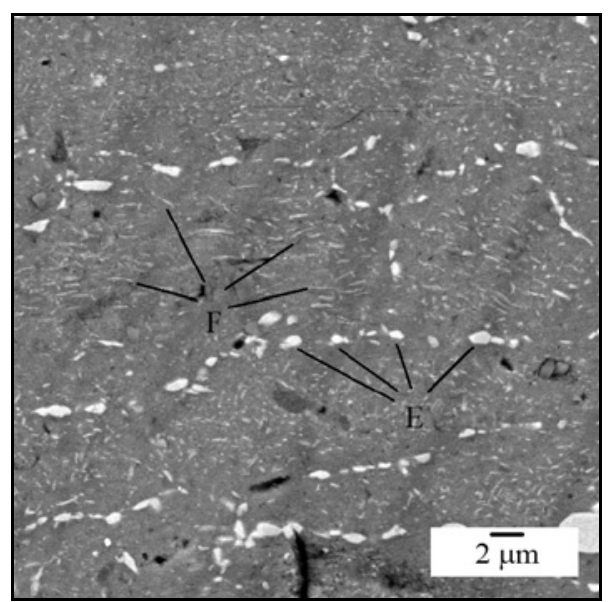

Fig. 8. HRSEM micrograph of the FSP processed material after $280 \mathrm{~h}$ at $300^{\circ} \mathrm{C}$.

while the nano-sized precipitates can be seen as well (type D). As shown in Fig. 8, after exposure to $300^{\circ} \mathrm{C}$, grain boundary decoration (type E in Fig. 8) becomes discernable, and fine platelet-like precipitates appear inside the grains (type F). Systematic precipitation analysis of aged AA2024-T3 specimens conducted by using TEM indicated that these precipitates contain either $\mathrm{Al}, \mathrm{Cu}$ and $\mathrm{Mg}$ or just $\mathrm{Al}$ and $\mathrm{Cu}$, as reported elsewhere $[12,13]$. After quantitative TEM study, a clear sub-grain structure was observed in the case of the parent material (for further details see [12]). Figure $9 \mathrm{a}$ is a Bright Field (BF) TEM micrograph of the parent material taken near $<001>$ Z.A. showing the dislocation structure comprising the sub-grain walls, while Fig. 9b shows the respectively selected area electron diffraction pattern.

A TEM study of the processed material yielded very low dislocation density. Besides, very few dislocation structures similar to those comprising the sub-
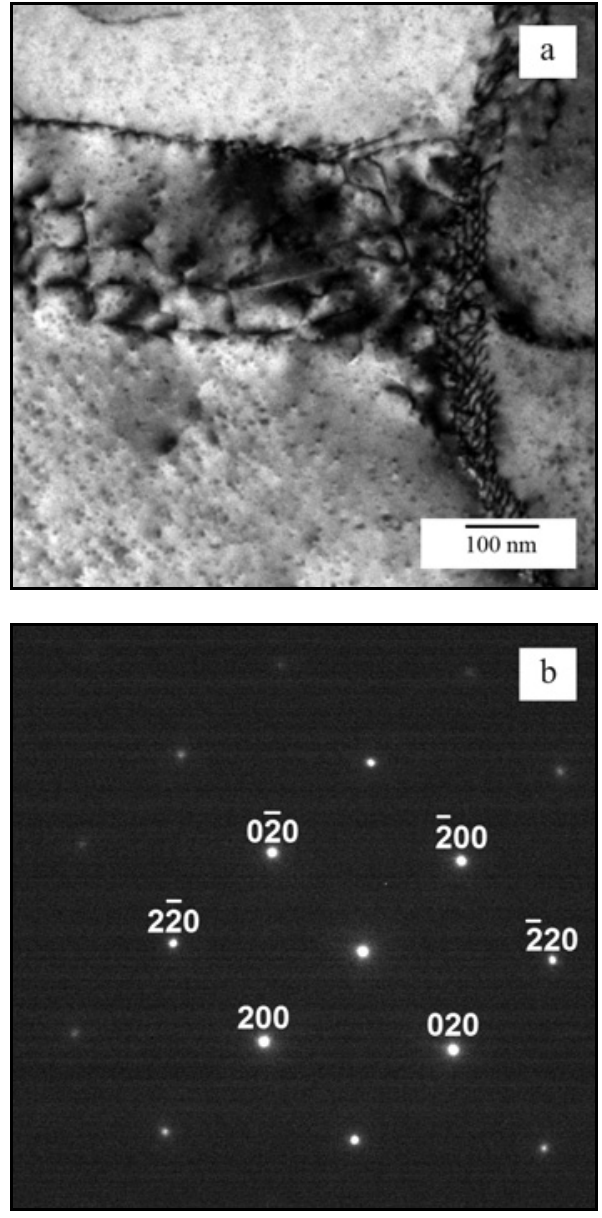

Fig. 9. (a) BF TEM micrograph of AA2024-T3 parent material taken near $<001>$ Z.A. and (b) selected area electron diffraction pattern of $<001>$ Z.A.

grain walls of the parent material were recorded. It seems that the microstructure consisted of ultrafine grains. In support of this claim, the TEM specimen was tilted to arbitrary zone axes of certain grains. This action was based on the fact that when a crystal is tilted to a certain zone axis, its BF image becomes darker because more energy goes from the incident beam to the diffracted beams. This phenomenon can be used to distinguish between two adjacent grains as well as to measure grain size. Figure 10a shows a BF TEM micrograph of the FSP processed material in its as-processed condition after grain 1 was tilted to $<011>$ Z.A. Figure 10b shows the respective selected area electron diffraction pattern taken from grain 1. The selected area electron diffraction pattern taken from grain 2 at the same time appears to be far from $<011>$ Z.A., not to mention that under these conditions grain 2 is very bright compared to grain 1 . Based on repetition of this procedure on a sufficiently large number of grains, it seems that both the absence of sub-grain walls and the results of these tilting exper- 

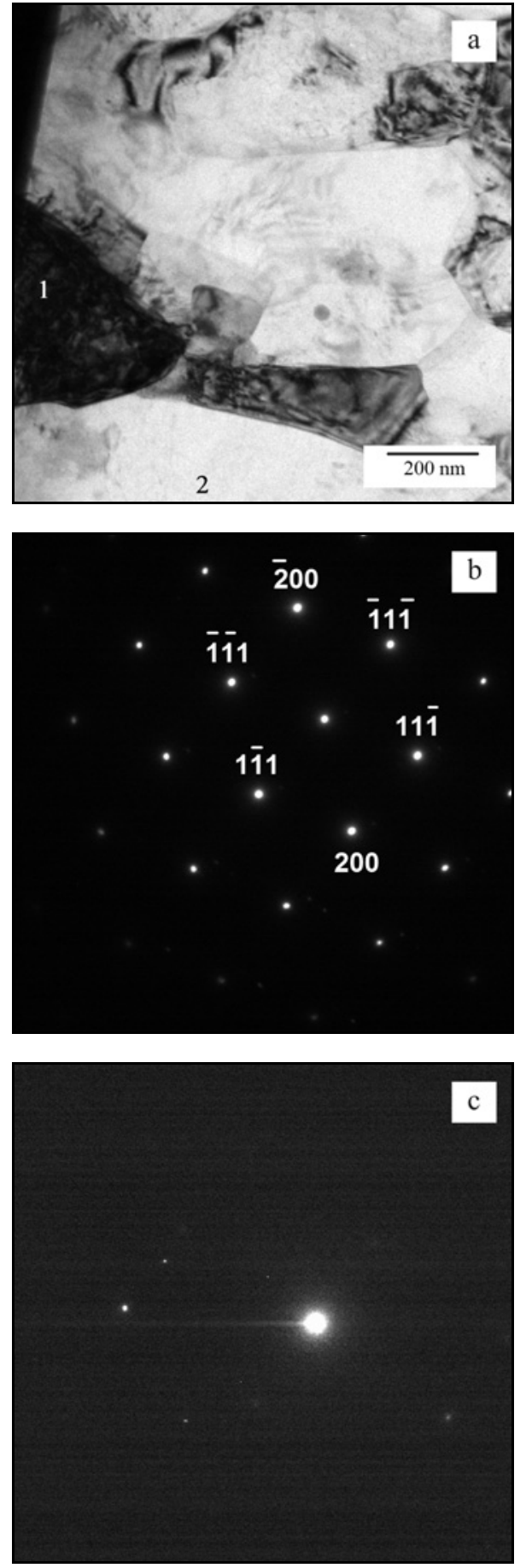

Fig. 10. (a) BF TEM micrograph of AA2024-T3 parent material taken when grain 1 tilted to $<011>$ Z.A., (b) selected area electron diffraction pattern of $<011>$ Z.A., and (c) selected area electron diffraction pattern taken from grain 2 .

iments show that the processed material is composed mostly of ultrafine grains created during FSP.

\section{Discussion}

As stated earlier, the aim of FSP is to obtain a stir zone with very fine grain size and hence improved mechanical properties. As Table 2 shows, in the current study, the tensile properties of the material after FSP are inferior to those of the parent material. However, the scattering of the results was much higher in the case of the FSP processed material, as can be seen from the standard deviations. For example, the standard deviation in the case of the tensile stress of the material that underwent FSP was about 33 times higher than the standard deviation of the tensile stress of the parent material. The high degree of scattering can be related either to non-homogeneity of the processed material or to defects introduced during FSP, indicating that further investigation is still required to determine the reason for this large scattering. The highest tensile stress measured for the material that underwent FSP was $419 \mathrm{MPa}$, which is $90.5 \%$ of the average tensile stress of the parent material, while the highest yield stress measured in case of material processed by FSP was $295 \mathrm{MPa}$, which is $81.5 \%$ of the average yield stress of the parent material. The best tensile results obtained by Nadammal et al. [2] reached $93 \%$ of the tensile strength of the parent material, compared to $90.5 \%$ in the current study. It should be noted that these values reported by Nadammal et al. [2] refer to bulk tensile specimens having a gage length of $60 \mathrm{~mm}$, a width of $6 \mathrm{~mm}$ and thickness of $5.6-5.7 \mathrm{~mm}$. In the current study that tested micro tensile specimens having a gage length of $6 \mathrm{~mm}$, width of $2 \mathrm{~mm}$ and thickness of about $1.8 \mathrm{~mm}$, the measured tensile stress was $30 \%$ higher than that of the parent material. This, in turn, leads to the conclusion that the mechanical properties change across the gage length and that higher tensile strength is expected when measured within $\pm 1 \mathrm{~mm}$ from the center. This conclusion is further supported by the hardness profile, which shows hardness variation between 114.9 and $125.3 \mathrm{HV} 0.2$ within the range of $\pm 1 \mathrm{~mm}$ from the center, compared to 107.8 to 129.9 HV0.2 within $\pm 2 \mathrm{~mm}$ from the center. These differences become markedly higher when reaching $4 \mathrm{~mm}$ from the center. Similar behavior was reported by Ghanbari et al. [8]. Keeping in mind that the hardness measured in the case of the parent metal was about $99 \mathrm{HV} 0.2$ parallel to its rolling direction, it appears that although the hardness values within $\pm 12 \mathrm{~mm}$ from the center varied with the depth, they were always higher than those of the parent metal. Thus, as has already been suggested, this contradiction between improved hardness and inferior tensile properties may be related to the introduction of defects during the FSP.

A comparison between Figs. 6 and 7 shows that in the refinement process the precipitates underwent during the FSP, the coarse precipitates observed in 
the parent material were broken into evenly dispersed precipitates $0.1-1 \mu \mathrm{m}$ in size. Improved mechanical properties at the stir zone may be related to the uniformity in size and homogenous dispersion of the precipitates. Figure 8 shows that the material that has undergone FSP is unstable. The precipitation process observed in Fig. 8, namely, grain boundary decoration, together with the appearance of fine platelet-like precipitates inside the grains and the chemical composition of these grains are similar to those observed at the parent material [12]. As stated elsewhere by the authors [12], the precipitate study of AA2024 continues to this day. Nevertheless, researchers seem to agree that two aging sequences take place. The first one is the $\theta$ aging sequence:

$$
\begin{gathered}
\alpha(\text { ssss }) \rightarrow \text { GP zones } \rightarrow \theta^{\prime \prime}\left(\mathrm{Al}_{3} \mathrm{Cu}\right) \rightarrow \theta^{\prime}\left(\mathrm{Al}_{2} \mathrm{Cu}\right) \rightarrow \\
\rightarrow \theta\left(\mathrm{Al}_{2} \mathrm{Cu}\right) .
\end{gathered}
$$

The second one is the $S$ aging sequence:

$$
\begin{aligned}
& \alpha(\text { ssss }) \rightarrow \text { GPBzones } \rightarrow S^{\prime \prime}\left(\mathrm{Al}_{2} \mathrm{CuMg}\right) \rightarrow \\
& \quad \rightarrow S^{\prime}\left(\mathrm{Al}_{2} \mathrm{CuMg}\right) \rightarrow S\left(\mathrm{Al}_{2} \mathrm{CuMg}\right) .
\end{aligned}
$$

Both sequences begin with a Super Saturated Solid Solution (SSSS) and end with stable precipitates. Aging experiments and chemical analysis of the precipitates showed that the precipitates are of both types $\mathrm{Al}-\mathrm{Cu}-\mathrm{Mg}$ and $\mathrm{Al}-\mathrm{Cu}$ - leading to the conclusion that both $S$ and $\theta$ aging sequences took place.

Until the 1990s it was believed that DRX does not occur in $\mathrm{Al}$ due to its high stacking fault energy. In turn, this high stacking fault energy is responsible for the appearance of a stable dislocation arrangement created by dynamic recovery [14, 15]. This perspective changed at the beginning of the 1990s. Prasad and Ravichandran [15] were among the first investigators to state that DRX does occur in Al. FSW, which was introduced at the same time $[1,2]$ and implied both high strain rates and high temperatures, is therefore expected to cause DRX. As of now researchers examining DRX during FSW or FSP of various Al alloys $[10,16-21]$ agree on the occurrence of DRX in Al alloys during FSW but mention different mechanisms as being responsible for its occurrence. Among these mechanisms are Strain-Induced Grain Boundary Migration (SIMB) acting simultaneously with PSN as the nucleation mechanisms for DRX [10]; Continuous Dynamic Recrystallization (CDRX) process based on dislocation glide assisted sub-grain rotation [16]; recrystallization via PSN [17]; Dynamic Recovery (DRV) followed by DRX without specifying the exact DRX mechanism [18, 19]; CDRX [20]; Discontinuous Dynamic Recrystallization (DDRX) [17, 20]; Geometric Dynamic Recrystallization (GDRX) [17, 20]; CDRX during which low angle sub-grain boundaries transformed to high angle boundaries [21].
The emergence of the fine equiaxed grains from the coarse elongated ones (Figs. 3, 4) as well as the disappearance of the dislocation networks and the sub-grain structure (Figs. 9, 10) indicate that a DRX process is taking place during FSP of AA2024 in the current study. It can be concluded that the high stacking fault energy of $\mathrm{Al}$ is responsible for the occurrence of DRV during thermo-mechanical processing of the 2024 aluminum alloy, in turn leading to the arrangement of dislocations into sub-grain boundaries as observed in the parent material after rolling. When, as in the case of FSP, high strain rates are applied, the material undergoes DRX. Certain discrepancies were found in the literature regarding the exact mechanism responsible for the DRX process. Hence it seems that further research is still required to fully understand the kinetics of the DRX process.

As for the technological potential of the process, it seems that FSP does improve the mechanical properties of the AA2024, as the hardness values achieved show. This claim is further supported by the microstructure obtained during FSB, which at the same time is grain refined and exhibits evenly dispersed uniform precipitates. Some additional improvements of the process are still required to eliminate the defects introduced during FSP and hence to achieve improved tensile properties.

\section{Conclusions}

- FSP was conducted on both sides of AA2024-T3 $3.125 \mathrm{~mm}$ thick plates. The processed material showed improved hardness but inferior tensile properties relative to the parent material. The inferior tensile properties together with their wide scattering are related to defects introduced during the FSP.

- During the FSP the coarse elongated grains of the parent material changed into fine equiaxed ones. Two kinds of precipitates were observed - very coarse precipitates tens of microns in size and evenly dispersed nano-sized precipitates. In the case of the material that underwent FSP, the coarse precipitates were broken into uniformly dispersed $0.1-1 \mu \mathrm{m}$ precipitates.

- The microstructure of the processed materials was found to be thermally unstable. After $280 \mathrm{~h}$ of exposure to $300^{\circ} \mathrm{C}$, grain boundary decoration was detected together with the appearance of fine plateletlike precipitates inside the grains.

- TEM study revealed a low angle sub-grain structure with dislocation network boundaries in the case of the parent metal. During FSP these were replaced with fine equiaxed grains having clear boundaries with no dislocation tangles.

- The high stacking fault energy of $\mathrm{Al}$ is assumed to be responsible for DRV during the thermo-mechanical processing of the 2024 aluminum alloy. In the case 
of the parent material after rolling, this leads to the arrangement of dislocations into sub-grain boundaries, while the high strain rates of the FSP lead to DRX. Further research is still required to determine which mechanism is responsible for DRX.

- FSP seems to offer the technological potential for improving the microstructure and mechanical properties of AA2024.

\section{Acknowledgements}

The assistance of Dr. Alexander Katz-Demyanetz with the HRSEM analysis is highly appreciated. Thanks are also due to Dr. Y. Kauffmann for his assistance with the TEM study and to Dr. G. Atiya for TEM specimen preparation.

This research project is partially funded by Ort Braude College of Engineering, Israel.

\section{References}

[1] Mishra, R. S., Mahoney, M. W., McFadden, S. X., Mara, N. A., Mukherjee, A. K.: Scripta Mater., 42, 2000, p. 163. doi:10.1016/S1359-6462(99)00329-2

[2] Nadammal, N., Kailas, S. V., Suwash, S.: Mater. Des., 65, 2015, p. 127. doi:10.1016/j.matdes.2014.09.005

[3] Charit, I., Mishra, R. S.: Mater. Sci. Eng. A, 359, 2003, p. 290. doi:10.1016/S0921-5093(03)00367-8

[4] Cavaliere, P.: J. Mater. Sci., 41, 2006, p. 4299. doi:10.1007/s10853-006-6996-7

[5] Suri, A., Sahai, A., Raj, K. H., Gupta, N. K.: Procedia Eng., 173, 2017, p. 679. doi:10.1016/j.proeng.2016.12.145

[6] Nadammal, N., Kailas, S. V., Szpunar, J., Suwas, S.: Metall. Mater. Trans. A, 48, 2017, p. 4247. doi:10.1007/s11661-017-4184-9

[7] Ren, J. G., Wang, L., Xu, D. K., Xie, L. Y., Zhang, Z. C.: Acta Metall. Sin. (Engl. Lett.), 30, 2017, p. 228. doi:10.1007/s40195-016-0489-8
[8] Ghanbari, D., Kasiri Asgharani, M., Amini, K.: Mechanika, 21, 2015, p. 430. doi:10.5755/j01.mech.21.6.12227

[9] El-Mahallawi, I., Ahmed, M. M. Z., Mahdy, A. A., Abdelmotagaly, A. M. M., Hoziefa, W., Refat, M.: In: Friction Stir Welding and Processing IX. Eds.: Hovanski, Y., Mishra, R., Sato, Y., Upadhyay, P., Yan, D. Pittsburgh, The Minerals, Metals \& Materials Society, Springer International Publishing 2017, p. 297. doi:10.1007/978-3-319-52383-5_29

[10] Nadammal, N., Kailas, S. V., Szpunar, J., Suwas, S.: Metall. Mater. Trans. A, 46, 2015, p. 2823. doi:10.1007/s11661-015-2902-8

[11] Davis, J. R., Allen, P.: Metals Handbook. Ohio, ASM International 1990.

[12] Regev, M., Rashkovsky, T., Cabibbo, M., Spigarelli, S.: J. Mater. Eng. Perform., 27, 2018, p. 5054. doi:10.1007/s11665-017-3122-8

[13] Regev, M., Spigarelli, S.: In: Proceedings of IIW 2017 International Conference. Shanghai, International Institute of Welding 2017, Paper F003, p. F13.

[14] Ponge, D., Bredehoft, M., Gottstein, G.: Scripta Mater., 37, 1997, p. 1796. doi:10.1016/S1359-6462(97)00346-1

[15] Prasad, Y., Ravichandran, N.: Bull. Mater. Sci., 14, 1991, p. 1241. doi:10.1007/BF02744618

[16] Jata, K. V., Semitin, S. L.: Scripta Mater., 43, 2000, p. 743.

[17] McNelly, T. R., Swaminathan, S., Su, J. Q.: Scripta Mater., 58, 2008, p. 349.

doi:10.1016/j.scriptamat.2007.09.064

[18] Bauri, R., Yadav, D., Suhas, G.: Mater. Sci. Eng. A, 528, 2011, p. 4732. doi:10.1016/j.msea.2011.02.085

[19] Dolatkhah, A., Golbabaei, P., Besharati Givi, M. K., Molaiekiya, F.: Mater. Des., 37, 2012, p. 458. doi:10.1016/j.matdes.2011.09.035

[20] Sharifitabar, M., Sarani, A., Khorshahian, M., Afarani, S.: Mater. Des., 32, 2011, p. 4164. doi:10.1016/j.matdes.2011.04.048

[21] Yadav, D., Bauri, R.: Mater. Sci. Eng. A, 528, 2011, p. 1326. doi:10.1016/j.msea.2010.10.035 